\title{
Low wintertime vitamin D levels in a sample of healthy young adults of diverse ancestry living in the Toronto area: associations with vitamin $D$ intake and skin pigmentation
}

\author{
Agnes Gozdzik ${ }^{1}$, Jodi Lynn Barta ${ }^{1}$, Hongyu Wu ${ }^{2}$, Dennis Wagner ${ }^{3,4}$, \\ David E Cole ${ }^{5}$, Reinhold Vieth ${ }^{3,4}$, Susan Whiting ${ }^{2}$ and Esteban J Parra*1
}

\begin{abstract}
Address: ${ }^{1}$ Department of Anthropology, University of Toronto at Mississauga, 3359 Mississauga Road North, Mississauga, Ontario L5L 1C6, Canada, ${ }^{2}$ College of Pharmacy and Nutrition, University of Saskatchewan, 110 Science Place, Saskatoon Saskatchewan, S7N 5C9, Canada, ${ }^{3}$ Department of Nutritional Sciences, FitzGerald Building, 150 College Street, University of Toronto, Toronto, Ontario M5S 3E2, Canada, ${ }^{4}$ Department of Pathology and Laboratory Medicine, Mount Sinai Hospital, 600 University Avenue, Toronto, Ontario M5G 1X5, Canada and ${ }^{5}$ Department of Laboratory Medicine and Pathobiology, Banting Institute, 100 College Street, University of Toronto, Toronto, Ontario M5G 1L5, Canada
\end{abstract}

Email: Agnes Gozdzik - agnes.gozdzik@utoronto.ca ; Jodi Lynn Barta - jl.barta@utoronto.ca; Hongyu Wu - hongyu.wu@usask.ca; Dennis Wagner - dennis.wagner@utoronto.ca; David E Cole - davidec.cole@utoronto.ca; Reinhold Vieth - rvieth@mtsinai.on.ca; Susan Whiting - susan.whiting@usask.ca; Esteban J Parra* - eparra@utm.utoronto.ca

* Corresponding author

Published: 26 September 2008

BMC Public Health 2008, 8:336 doi:10.1 I86/I47|-2458-8-336
Received: 27 March 2008

Accepted: 26 September 2008

This article is available from: http://www.biomedcentral.com//47/-2458/8/336

(c) 2008 Gozdzik et al; licensee BioMed Central Ltd.

This is an Open Access article distributed under the terms of the Creative Commons Attribution License (http://creativecommons.org/licenses/by/2.0), which permits unrestricted use, distribution, and reproduction in any medium, provided the original work is properly cited.

\begin{abstract}
Background: Vitamin $\mathrm{D}$ plays a critical role in bone metabolism and many cellular and immunological processes. Recent research indicates that concentrations of serum 25hydroxyvitamin $D[25(\mathrm{OH}) \mathrm{D}]$, the main indicator of vitamin $\mathrm{D}$ status, should be in excess of 75 nmol/L. Low levels of 25(OH)D have been associated with several chronic and infectious diseases. Previous studies have reported that many otherwise healthy adults of European ancestry living in Canada have low vitamin $D$ concentrations during the wintertime. However, those of nonEuropean ancestry are at a higher risk of having low vitamin $D$ levels. The main goal of this study was to examine the vitamin $D$ status and vitamin $D$ intake of young Canadian adults of diverse ancestry during the winter months.
\end{abstract}

Methods: One hundred and seven (107) healthy young adults self-reporting their ancestry were recruited for this study. Each participant was tested for serum $25(\mathrm{OH}) \mathrm{D}$ concentrations and related biochemistry, skin pigmentation indices and basic anthropometric measures. A seven-day food diary was used to assess their vitamin D intake. An ANOVA was used to test for significant differences in the variables among groups of different ancestry. Linear regression was employed to assess the impact of relevant variables on serum $25(\mathrm{OH}) \mathrm{D}$ concentrations.

Results: More than $93 \%$ of the total sample had concentrations below $75 \mathrm{nmol} / \mathrm{L}$. Almost threequarters of the subjects had concentrations below $50 \mathrm{nmol} / \mathrm{L}$. There were significant differences in serum $25(\mathrm{OH}) D$ levels $(p<0.00 \mathrm{I})$ and vitamin $D$ intake $(p=0.034)$ between population groups. Only the European group had a mean vitamin $D$ intake exceeding the current Recommended Adequate Intake (RAI = $200 \mathrm{IU} /$ day). Total vitamin $\mathrm{D}$ intake (from diet and supplements) was significantly associated with $25(\mathrm{OH}) \mathrm{D}$ levels $(\mathrm{p}<0.00 \mathrm{I})$. Skin pigmentation, assessed by measuring skin melanin content, showed an inverse relationship with serum 25(OH)D $(p=0.033)$. 


\begin{abstract}
Conclusion: We observe that low vitamin D levels are more prevalent in our sample of young healthy adults than previously reported, particularly amongst those of non-European ancestry. Major factors influencing 25(OH)D levels were vitamin $D$ intake and skin pigmentation. These data suggest a need to increase vitamin $D$ intake either through improved fortification and/or supplementation.
\end{abstract}

\section{Background}

Vitamin D plays a critical role in bone metabolism and many cellular and immunological processes [1-4]. Low levels of vitamin $\mathrm{D}$ have been associated with various chronic and infectious diseases including cancer, multiple sclerosis, diabetes, rheumatoid arthritis, osteoporosis, cardiovascular disease, and microbial infections [5-13]. Vitamin $\mathrm{D}$ is synthesized in the skin upon exposure to the sun's ultraviolet B radiation (UVB) [12]. Vitamin D can also be acquired from the diet from sources where it occurs naturally (such as fatty fish, fish oil and eggs), from fortified products (such as milk and orange juice) and from supplements [12]. For many people, exposure of their skin to UVB is the primary source of their vitamin D $[4,14]$. However, at latitudes far from the equator, such as Canada, the amount of UVB available from sunlight during the winter months is inadequate to allow cutaneous vitamin D synthesis $[4,15]$.

Several other factors can affect vitamin D concentrations, including: skin pigmentation (melanin, the major natural pigment in the skin, interferes with cutaneous production of vitamin D) $[16,17]$; age (the skin loses the ability to synthesize vitamin D with increased age) [14,18]; weight (higher adiposity has been associated with lower vitamin D levels) [19-22]; deliberate avoidance of sun exposure and/or use of sunblock (due to sun safety or cultural reasons) $[12,23]$; malabsorption disorders which affect the body's ability to absorb vitamin D (including celiac disease, Crohn's disease, cystic fibrosis) [24]; diseases and disorders of the kidneys and/or liver that affect vitamin D metabolism [12] and use of certain medications (including anticonvulsants, anti-rejection medications, corticosteroids) $[12,25]$.

The standard method for the determination of vitamin $\mathrm{D}$ status tests the circulating concentration of serum 25hydroxyvitamin D [25(OH)D], which measures the amount of vitamin $\mathrm{D}$ coming into the body from all sources (cutaneous synthesis, diet or supplements) [26]. Previous efforts to assess optimal serum 25(OH)D levels focused on the role of vitamin $\mathrm{D}$ in bone health, and the optimal 25(OH)D concentration was defined as the concentration that maximally suppressed serum parathyroid hormone $(\mathrm{PTH})$ and promoted maximum calcium absorption [27]. In general, vitamin D "deficiency" was classified as concentrations below 25-27.5 $\mathrm{nmol} / \mathrm{L}$
$[28,29]$. Levels below these cutoffs are associated with calcium malabsorption, severe hyperparathyroidism and vitamin D rickets or osteomalacia [30]. Some past studies have considered serum 25(OH)D levels of 40-50 nmol/L as the low end of the normal range [31,32]. However, other studies have shown that PTH levels $[33,34]$ and calcium absorption [35] are not optimized until serum 25(OH)D levels reach approximately $80 \mathrm{nmol} / \mathrm{L}$. Most vitamin $\mathrm{D}$ researchers now recognize that concentrations of serum $25(\mathrm{OH}) \mathrm{D}$ should be in excess of $75 \mathrm{nmol} / \mathrm{L}$ for multiple health outcomes, not only bone health $[27,36]$. Accordingly, recent reports refer to serum 25(OH)D levels $>75 \mathrm{nmol} / \mathrm{L}$ as "optimal", between $75 \mathrm{nmol} / \mathrm{L}$ and 50 $\mathrm{nmol} / \mathrm{L}$ as "insufficient" and $<50 \mathrm{nmol} / \mathrm{L}$ as "deficient" [37]. In our study, we report the percentage of the individuals in our sample under three widely used cutoffs, 25 $\mathrm{nmol} / \mathrm{L}, 50 \mathrm{nmol} / \mathrm{L}$ and $75 \mathrm{nmol} / \mathrm{L}$, and we consider $25(\mathrm{OH}) \mathrm{D}$ levels $>75 \mathrm{nmol} / \mathrm{L}$ as optimal.

Previous research indicates that vitamin D concentrations are low in many otherwise healthy Canadian adults, particularly during the winter months [28,38]. Vieth et al. [28] studied a sample of young women (18-35 years old) in Toronto and found that $21 \%$ of white women, $31.9 \%$ of non-white women (a group which combined women of First Nations, South Asian, Indo-Asian and East Asian ancestries) and $25 \%$ of black women had serum concentrations below $40 \mathrm{nmol} / \mathrm{L}$ during the winter months. Rucker et al. [38] examined a group of men and women of mostly European ancestry living in western Canada and observed that $20 \%$ had serum concentrations below 40 $\mathrm{nmol} / \mathrm{L}, 39 \%$ had serum concentrations below $50 \mathrm{nmol} /$ $\mathrm{L}$ and $86 \%$ had serum concentrations below $80 \mathrm{nmol} / \mathrm{L}$.

Past studies examining the vitamin D status of Canadians have focused primarily on individuals of European ancestry and have included few or no individuals of other ancestries, who constitute a large proportion of the population of Canadian metropolitan areas [39]. Individuals of European ancestry have a lower risk of vitamin D insufficiency because they have low cutaneous melanin levels. It is well known that melanin interferes with the production of vitamin $\mathrm{D}$ in the skin and that individuals with darker skin pigmentation are at increased risk of vitamin D insufficiency [40]. Therefore, it is likely that the prevalence of insufficiency among all Canadians exceeds currently reported estimates $[28,38]$. Additionally, previous studies 
in Canada have failed to measure pigmentation quantitatively. Therefore, it is critical to expand the existing research to explore how differences in skin pigmentation [41] or other factors potentially associated with vitamin D levels, such as vitamin D dietary intake, supplementation or sun exposure, affect the vitamin D status of broadly defined population groups. Results of such studies will be important to inform public health policies regarding fortification and recommendation of intakes in order to ensure that all Canadians have sufficient vitamin D levels.

The aim of this study is to evaluate the wintertime vitamin D status and dietary vitamin D intake of young adults of diverse ancestry in Canada, and to assess the impact of quantitatively measured skin pigmentation and dietary intake on serum $25(\mathrm{OH}) \mathrm{D}$ levels.

\section{Methods \\ Study Population and Recruitment}

Study recruitment took place at the University of Toronto at Mississauga (Ontario, Canada) during the winter of 2007. The study was advertised to the University of Toronto community online, and also via the use of advertisements at the University of Toronto at Mississauga campus. Most of the participants were either students or employees of the university.

Participant eligibility for the study was assessed using a questionnaire that was completed prior to study enrollment. The following were exclusion criteria: age (only participants between the ages of 18 and 30 were recruited for this study), diagnosis of kidney/liver damage or other disorders or diseases that may affect vitamin D metabolism or absorption (including osteomalacia, osteopenia, Crohn's disease, etc.), use of medications that affect vitamin D metabolism (steroids, anticonvulsants, etc.) and recent exposure to UVB (such as visits to tanning salons or trips to sunny destinations less than three months before recruitment). Use of vitamin D supplements was not an exclusionary variable because we were interested in evaluating how many participants take vitamin D supplements, and the effect of supplementation on 25(OH)D levels. Participant ancestry was assessed based on responses to a personal questionnaire, which asked questions pertaining to the birthplace, migration history, native languages and self-reported ethnicity of the participants, their parents and grandparents.

In total, one hundred and seven subjects (58 females, 49 males) were eligible and agreed to participate. This study was approved by the University of Toronto Health Sciences Research Ethics Board, and all participants provided written informed consent.

\section{Data Collection}

Participants met with the researchers twice during the study. During the initial visit, which took place between February 14 and March 16, the participants completed a personal questionnaire that assessed ancestry (personal, parental, and grandparental places of birth, ethnicity, language, migration history, and present residence). Anthropometric measurements (weight and height) were also taken, from which body mass index (BMI) was calculated for each participant. All participants were instructed to complete a 7-day food diary, which recorded all beverages and food items consumed over a 7-day period, and a blood sample was drawn. During the second visit, which in most cases took place within two weeks of the first visit, participants returned the completed food diaries and were reimbursed for their participation.

\section{Measuring Pigmentation using Reflectometry}

Melanin content was measured in the inner upper arm using a narrow band reflectometer during the initial visit (Dermaspectrometer, Cortex Technology, Hadsund, Denmark) [42]. Measurements taken on the upper inner arm represent constitutive skin pigmentation (pigmentation in unexposed areas of the skin). The Dermaspectrometer estimates the amount of melanin in the skin from the amount of light reflected back to the machine in the red and green wavelengths of the light spectrum [42]. Skin color is primarily influenced by two pigments: hemoglobin and melanin, with hemoglobin showing a large optical absorption peak in the green wavelengths and a sharp drop off in the red wavelengths (this is why blood appears red), while melanin shows absorption of light at all wavelengths [42]. Based on the differences in the spectral curves of the two pigments, Diffey et al. [43] suggested that the reflectance of light in the red spectrum would generate an estimate of the melanin content of human skin, following the equation, Melanin $=\log _{10}$ ( $1 \%$ red reflectance). Melanin Index values calculated using the Dermaspectrometer range from the low 20s to more than 100 , with individuals with the lightest skin pigmentation having the lowest values and those with the darkest pigmentation having the highest [42].

\section{Biochemical Analyses}

An aliquot of whole blood was centrifuged and the serum fraction was removed after clotting and stored at $-80^{\circ} \mathrm{C}$. Serum parathyroid hormone (PTH), calcium, phosphate, and creatinine, were measured on the automated Modular Analytics Serum Work Area (Roche, Basel, Switzerland). Serum 25-hydroxyvitamin D [25(OH)D] concentrations were determined by the DiaSorin "25-OH Vitamin D TOTAL" competitive chemiluminescence immunoassay on the automated LIAISON ${ }^{\circledR}$ analyzer (Stillwater, MN). This method has $100 \%$ specificity for both $25(\mathrm{OH})$ vita- 
min $\mathrm{D}_{2}$ and $25(\mathrm{OH})$ vitamin $\mathrm{D}_{3}$. This assay has a limit of detection of $10 \mathrm{nmol} / \mathrm{L}$, an intra-assay coefficient of variation (CV) of 5\%, and an inter-assay CV of 7\%. Samples were analyzed in one continuous batch with quality control samples inserted at periodic intervals.

This 25(OH)D "total" method was previously validated with a different sample set in which serum 25(OH)D was measured using both the "total" method and the DiaSorin radioimmunoassay (RIA) (DiaSorin, Stillwater, MN). A comparison showed a strong correlation between the methods $\left(r^{2}=0.814\right)$. Statistically, serum $25(\mathrm{OH}) \mathrm{D}$ concentrations determined by both methods were indistinguishable from one another ( $\mathrm{p}=0.17$, paired $\mathrm{t}$-test).

\section{Nutritional Analyses}

Daily intake of vitamin D from dietary and supplemental sources was estimated using a 7-day food diary. Subjects were provided with portion size aids and recorded their food, beverage and supplement intake for seven consecutive days. Vitamin D intake was analyzed with the computer program Food Processor (version 8.0 and its revisions, ESHA Research Inc., Salem OR, which included the 1997 Canadian Nutrient File from Health Canada); Canadian foods were always chosen where fortification was different from USA, e.g., margarine, breakfast cereals.

\section{Statistical Analyses}

Differences between population groups in serum $25(\mathrm{OH}) \mathrm{D}$ levels and vitamin D intake were evaluated using ANOVA. For these analyses, serum 25(OH)D was log transformed and vitamin D intake was transformed using the square-root transformation. The effects of age, sex, BMI, total vitamin D intake and skin pigmentation (melanin content) on log serum 25(OH)D levels were explored using multiple linear regression. All statistical tests were performed with SPSS (Version 15.0, SPSS Inc., 2006). A power analysis using the software $G^{*}$ Power (Version 3) [44] indicated that, using a significance level of $\alpha$ $=0.05$, our study has approximately $87 \%$ power to detect a large effect size $(\mathrm{f}=0.40)$ in an ANOVA analysis (with a sample size of 75 individuals in three groups) and approximately $87 \%$ power to detect a medium effect size $\left(\mathrm{f}^{2}=\right.$ 0.15 ) in a multiple regression analysis (with a sample size of 107 individuals with five predictors).

\section{Results \\ Sample Characteristics}

Participants were divided into broadly defined subsets based on self-reported geographic origin gathered in the personal questionnaire. Most of the participants self-identified as being of either African, East Asian, European or South Asian ancestry. Individuals who reported being of other ancestries or of multiple ancestries were placed into another subgroup designated as "Other". Table 1 summarizes the clinical and biochemical characteristics for the total sample and the three population groups well represented in the sample (East Asian, European and South Asian). Because of the small sample size of individuals in the African and "Other" subgroups, these subgroups were not included in the statistical analyses. The following variables showed significant differences between the sexes: age $($ mean male $=21.5$, female mean $=20.1 \mathrm{p}=0.002)$, BMI $($ male mean $=21.2$ female mean $=18.7, p=0.002)$, creatinine $($ male mean $=81.4$, female mean $=59.4, \mathrm{p}<$ 0.001 ) and calcium (male mean $=2.43$, female mean $=$ 2.38, $\mathrm{p}=0.003$ ). An ANOVA showed that, after controlling for age and sex, there were no significant differences in PTH, calcium, phosphate, and creatinine concentrations between the three ancestral groups (European, East Asian and South Asian). However, there were significant differences in serum 25(OH)D concentrations among the three groups (see below). The mean melanin index for the total sample was 33.0, and ranged from 22.4-53.5. Mean melanin index values (and ranges) for the different groups were as follows: East Asian $=32.0$ (range 26.7-40.4); European $=28.6($ range 22.4-32.3); and South Asian = 38.3 (range 29.8-53.5). An ANOVA showed that that there was a significant difference in pigmentation among the groups, even after controlling for sex and age.

Table I: Description of the variables collected in the global sample, and stratified by ancestry.

\begin{tabular}{|c|c|c|c|c|}
\hline & Total Sample* & East Asian & European & South Asian \\
\hline N (Females, Males) & $107(57,50)$ & $27(17,10)$ & $32(16,16)$ & $32(19,13)$ \\
\hline Age & $21(18,25)$ & $21(18,24)$ & $21(18,26)$ & $21(18,25)$ \\
\hline BMI & $19.9(15.0,26.6)$ & $18.6(14.9,27.4)$ & $20.7(16.5,28.0)$ & $19.9(14.4,25.8)$ \\
\hline Melanin Index & $35.1(26.3,52.7)$ & $32.0(27.5,36.8)$ & $28.6(25.2,32.0)$ & $38.3(31.8,46.8)$ \\
\hline $25(\mathrm{OH}) \mathrm{D}(\mathrm{nmol} / \mathrm{L})$ & $39.4(15.3,77.1)$ & $34.5(15.1,71.5)$ & $55.9(26.7,96.3)$ & $30.5(13.3,51.6)^{\#}$ \\
\hline PTH (pmol/L) & $3.4(1.8,5.4)$ & $3.1(1.9,4.7)$ & $3.1(1.8,5.2)$ & $3.5(1.7,5.3)$ \\
\hline Calcium (nmol/L) & $2.4(2.3,2.5)$ & $2.4(2.2,2.6)$ & $2.4(2.3,2.5)$ & $2.4(2.3,2.5)$ \\
\hline Phosphate (nmol/L) & $1.1(0.8,1.3)$ & $1.1(0.9,1.3)$ & I.I $(0.8,1.3)$ & I.I $(0.8,1.4)$ \\
\hline Creatinine $(\mu \mathrm{mol} / \mathrm{L})$ & $69.4(48.0,92.7)$ & $66.5(45.2,92.7)$ & $72.9(56.6,90.9)$ & $66.8(48.0,91.0)$ \\
\hline
\end{tabular}

Mean values and 5 th and 95 th percentiles (in parentheses) are reported.*Total sample comprises individuals of African ancestry $(n=7)$, East Asian ancestry $(n=27)$, European ancestry $(n=32)$, Other ancestry $(n=9)$, and South Asian ancestry $(n=32)$. \#25(OH)D measurements were not available for one individual of South Asian ancestry, hence $n=106$ for this variable. 


\section{Vitamin D Status and Ancestry}

Figure 1 shows the distribution of serum 25(OH)D concentrations according to ancestry. Only one individual had serum measurements below the $10 \mathrm{nmol} / \mathrm{L}$ limit of detection. Table 2 reports vitamin $\mathrm{D}$ status for all participants, and stratified according to ancestry using three widely used cutoffs: $<25 \mathrm{nmol} / \mathrm{L},<50 \mathrm{nmol} / \mathrm{L},<75$ $\mathrm{nmol} / \mathrm{L}$ and finally, optimal vitamin D levels $(\geq 75 \mathrm{nmol} /$ L).

The mean serum $25(\mathrm{OH}) \mathrm{D}$ concentration in the global sample was $39.4 \pm 21 \mathrm{nmol} / \mathrm{L}$ (range: $10-111 \mathrm{nmol} / \mathrm{L}$ ). The mean was highest in Europeans (55.9, range 16.4$110.0 \mathrm{nmol} / \mathrm{L}$ ), followed by East Asians (34.5, range 10.9-111.0 nmol/L) and lowest in South Asians (30.5, range $10-57.8 \mathrm{nmol} / \mathrm{L})$. Only $6.6 \%$ of the total sample had optimal 25(OH)D concentrations, defined as > 75 $\mathrm{nmol} / \mathrm{L}$. Almost three-quarters (74\%) of the sample had concentrations below $50 \mathrm{nmol} / \mathrm{L}$. More importantly, 25(OH)D levels showed substantial variation according to ancestry: $34.4 \%$ of the subjects of European ancestry had concentrations $<50 \mathrm{nmol} / \mathrm{L}$, while $85.2 \%$ of East Asians and 93.5\% of South Asians had 25(OH)D levels < $50 \mathrm{nmol} / \mathrm{L}$ (Fisher's exact test, $\mathrm{p}<0.001$ ).

Analysis of the ancestry-specific group means for log serum $25(\mathrm{OH}) \mathrm{D}$ concentrations by ANOVA showed significant differences for the European, East Asian and South Asian samples ( $\mathrm{p}<0.001)$. Post-hoc tests (Tukey HSD) revealed that these results were driven by the significantly higher serum $25(\mathrm{OH}) \mathrm{D}$ concentrations in the European group with respect to the other two groups: East Asian and European ( $\mathrm{p}<0.001)$, and South Asian and European $(\mathrm{p}<0.001)$. No significant pairwise differences in mean serum 25(OH)D were found between East Asians and South Asians $(\mathrm{p}=0.775)$.

\section{Vitamin D Intake and Ancestry}

Mean vitamin D intake in the total sample and stratified by ancestry is reported in Table 3. Mean daily total vitamin D intake was substantially higher in the European sample $(231.0 \pm 173.5$ International Units-IU) than in the East Asian (133.4 $\pm 101.7 \mathrm{IU})$ and South Asian (164.3 \pm 144.3 IU) samples. In all groups, mean daily dietary intake of vitamin $\mathrm{D}$ was greater than mean daily intake from supplements. Only $22.9 \%$ of the participants reported the use of supplements. Vitamin D intake from food sources was highest in the European group as was vitamin D intake from supplements.

Total daily vitamin D intake (from diet and supplements, transformed using the square-root transformation) differed significantly among groups (ANOVA for East Asian, European and South Asian samples; $\mathrm{p}=0.034)$. No significant differences in vitamin $\mathrm{D}$ intake were observed between the sexes.

The current recommendation for Adequate Intake (AI) of vitamin D is $200 \mathrm{IU} /$ day for individuals between the ages of 19-50 [29]. The availability of vitamin D intake data in our study allowed us to further evaluate 25(OH)D levels in individuals with a vitamin $\mathrm{D}$ daily intake higher than 200 IU. When the sample was stratified according to total vitamin $\mathrm{D}$ intake and we analyzed only the $25(\mathrm{OH}) \mathrm{D} \mathrm{lev-}$ els of the individuals with intakes higher than $200 \mathrm{IU} /$ day, $84.4 \%$ of the individuals had serum $25(\mathrm{OH}) \mathrm{D}$ concentrations $<75 \mathrm{nmol} / \mathrm{L}$ and $40.6 \%$ of the individuals showed 25(OH)D levels $<50 \mathrm{nmol} / \mathrm{L}$.

\section{Factors Affecting Vitamin D Status}

Several variables are known to affect vitamin D status and these were assessed for their influence on serum 25(OH)D: age [14,18], BMI [19-22], vitamin D intake $[37,45]$ and constitutive skin pigmentation $[16,17,46]$. A linear regression analysis was performed with log serum as the dependent variable and age, sex, BMI, total vitamin $\mathrm{D}$ intake and skin pigmentation as the independent variables. The regression analysis revealed that almost 35\% of the variation in log serum 25(OH)D concentrations was explained by the linear combination of the variables tested $\left(\mathrm{r}^{2}=0.339, \mathrm{~F}_{(5,98)}=10.049, \mathrm{p}<0.001\right)$. Table 4 shows the bivariate and partial correlations for each of the variables tested in the model. Only two of the five tested variables had a statistically significant relationship with serum $25(\mathrm{OH}) \mathrm{D}$ concentrations: total vitamin $\mathrm{D}$ intake $(\mathrm{p}$ $<0.001)$ and skin pigmentation $(\mathrm{p}=0.033)$. On the basis of this analysis, we can infer that both total vitamin $\mathrm{D}$ intake and constitutive skin pigmentation are predictors of serum $25(\mathrm{OH}) \mathrm{D}$ in this sample. Total vitamin $\mathrm{D}$ intake showed a positive correlation with total vitamin $\mathrm{D}$ intake

Table 2: Wintertime vitamin D status in the global sample, and stratified by ancestry

\begin{tabular}{lcccc}
\hline Vitamin D Status & Total Sample* $(n=106)$ & East Asian $(n=27)$ & European $(n=32)$ & South Asian $(n=3 I)$ \\
\hline$\%<25 \mathrm{nmol} / \mathrm{L}$ & 25.5 & 29.6 & 6.2 & 35.5 \\
$\%<50 \mathrm{nmol} / \mathrm{L}$ & 73.6 & 85.2 & 34.4 & 93.5 \\
$\%<75 \mathrm{nmol} / \mathrm{L}$ & 93.4 & 92.6 & 84.4 & 100.0 \\
$\%>75 \mathrm{nmol} / \mathrm{L}$ & 6.6 & 7.4 & 15.6 & 0.0
\end{tabular}

*Total sample comprises individuals of African ancestry $(n=7)$, East Asian ancestry $(n=27)$, European ancestry $(n=32)$, Other ancestry $(n=9)$, and South Asian ancestry $(n=31) .25(\mathrm{OH}) \mathrm{D}$ measurements were not available for one individual of South Asian ancestry. 


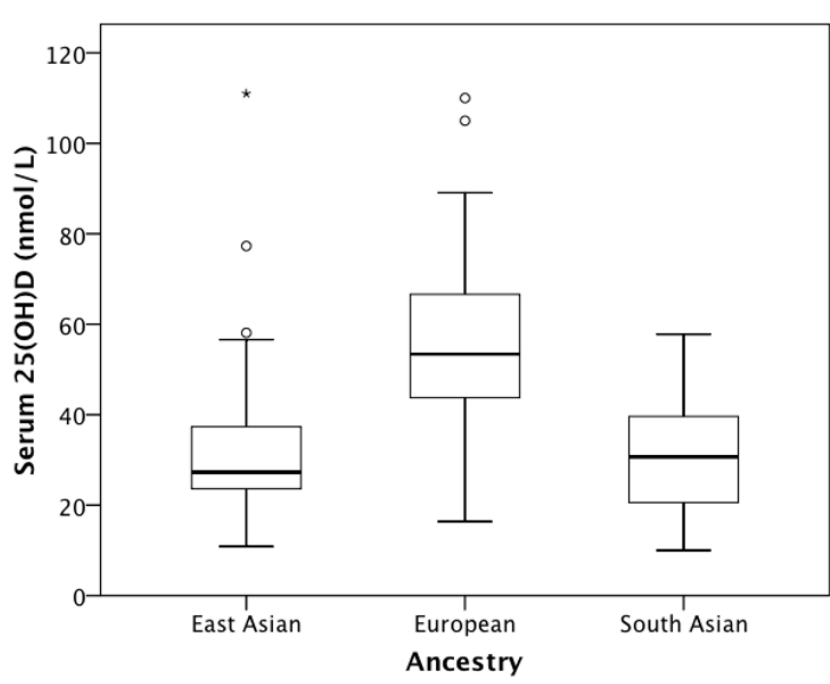

Figure I

Boxplot showing serum 25(OH)D concentrations by ancestry. The boxplot presents five statistics: the top of the box represents the $75^{\text {th }}$ percentile, the line within the box represents the median and the bottom of the box represents the $25^{\text {th }}$ percentile, while the whiskers correspond to the minimum and maximum values that are not outliers. The points above or below the whiskers represent outliers. The asterisk (*) on the plot corresponds to an outlier whose serum levels were the highest reported in this study (I IO $\mathrm{nmol} / \mathrm{L})$.

and it alone explained $30.4 \%$ of the variance in serum $25(\mathrm{OH}) \mathrm{D}$ concentrations. Controlling for all the other variables in the analysis (age, BMI, sex and total vitamin D intake), total vitamin D intake explained $28.9 \%$ of the variance in serum 25(OH)D (see partial correlations in Table 4). Constitutive skin pigmentation shows a negative correlation with serum 25(OH)D and explained $6.5 \%$ of the variation in serum $25(\mathrm{OH}) \mathrm{D}$. When controlling for all the other variables, skin pigmentation explained $4.5 \%$ of the variance in serum $25(\mathrm{OH}) \mathrm{D}$.

Examination of the partial regression plots suggested the presence of an outlier and the dataset was checked for outliers by examining casewise diagnostics, leverage statistic (h) and Mahalanobis distance. The following criteria were used: casewise diagnostics set at $>3$ standard deviations, $\mathrm{h}>0.2$ and Mahalanobis distance $>20.52\left(\chi^{2}=20.52\right.$, with $\mathrm{df}=5$ and $\alpha=0.001)$. One outlier was identified by both leverage statistics and Mahalanobis distance. This case was investigated and it was observed that this participants' pigmentation was the darkest in the sample (Melanin Index was 15 points higher than the second darkest person). The outlier was removed and the regression was performed again with no report of other outliers.

With the removal of the outlier, the strength of the multiple regression model improved $\left(\mathrm{r}^{2}=0.374, \mathrm{~F}_{(5,97)}=\right.$ $11.597, \mathrm{p}<0.001)$. Once again, only total vitamin $\mathrm{D}$ intake $(\mathrm{p}<0.001)$ and skin pigmentation $(\mathrm{p}=0.003)$ had a significant effect on serum 25(OH)D concentrations. With the removal of the outlier, total vitamin $\mathrm{D}$ intake explained $30.9 \%$ of the variation in serum $25(\mathrm{OH}) \mathrm{D}$. The relationship between serum $25(\mathrm{OH}) \mathrm{D}$ and skin pigmentation also increased with the removal of the outlier and skin pigmentation accounted for $9.2 \%$ of the variation in serum $25(\mathrm{OH}) \mathrm{D}$ (compared to $6.5 \%$ when the outlier was present in the dataset).

\section{Discussion}

Our findings indicate that vitamin $\mathrm{D}$ levels are very low in a cohort of healthy young adults living in Southern Ontario, particularly among those of non-European ancestry. Two previous studies examined vitamin D status in the Canadian population, but both primarily sampled individuals of European ancestry $[28,38]$. Our study is consistent with Rucker et al. [38] in that most individuals had serum concentrations below the levels considered optimal by most vitamin D experts $(86 \%$ had serum 25(OH)D concentrations below $80 \mathrm{nmol} / \mathrm{L}$ in Rucker et al. compared to $93 \%$ of all participants in our study having serum $25(\mathrm{OH}) \mathrm{D}<75 \mathrm{nmol} / \mathrm{L})$. However, a key finding of our study is that there were significant differences in vitamin D levels among broadly defined ancestral groups living in Canada. Two previous Canadian studies defined vitamin D insufficiency as serum 25(OH)D levels $<40$ $\mathrm{nmol} / \mathrm{L}$, and in these studies $21 \%$ and $20 \%$ of individuals of European ancestry had concentrations lower than this cutoff $[28,38]$. In our sample, $22 \%$ of individuals of European ancestry had 25(OH)D levels less than the $40 \mathrm{nmol} /$

Table 3: Mean dietary, supplemental and total vitamin D intake (reported as International Units, IU, per day) in the global sample, and stratified by ancestry.

\begin{tabular}{lcccc}
\hline Sources (IU/day) & Total Sample $(n=105)$ & East Asian $(n=27)$ & European $(n=3 I)$ & South Asian $(n=32)$ \\
\hline Dietary & $121.0(17.1,309.5)$ & $96.6(6.71,213.1)$ & $141.6(29.1,321.4)$ & $129.9(21.9,355.3)$ \\
Supplemental & $50.7(0,388.5)$ & $36.8(0,171.43)$ & $89.4(0,400)$ & $34.4(0,214.1)$ \\
Total & $171.7(19.7,464.3)$ & $133.4(8.0,311.5)$ & $231.0(34.03,582.67)$ & $164.3(27.7,391.7)$
\end{tabular}

The 5th and 95th percentiles are indicated in parentheses. *Total sample comprises individuals of African ancestry $(n=7)$, East Asian ancestry $(n=$ 27), European ancestry $(n=31)$, Other ancestry $(n=8)$, and South Asian ancestry $(n=32)$. Vitamin $D$ intake data were not available for one individual of European ancestry and one individual of Other ancestry. 
Table 4: Bivariate and partial correlations between serum 25(OH)D and five relevant variables.

\begin{tabular}{lccc}
\hline Predictor & \multicolumn{2}{c}{ Correlations } & $p$ \\
\hline & Bivariate* & Partial\# & \\
\hline Age & 0.024 & 0.081 & 0.425 \\
BMI & -0.051 & 0.000 & 0.997 \\
Sex & -0.080 & 0.003 & 0.977 \\
Skin Pigmentation & -0.254 & -0.213 & 0.033 \\
Total Vitamin D Intake & 0.551 & 0.538 & $<0.001$ \\
\hline
\end{tabular}

*Bivariate correlations represent the correlation between serum $25(\mathrm{OH}) \mathrm{D}$ and each variable. \#Partial correlations represent the correlation between serum $25(\mathrm{OH}) \mathrm{D}$ and each variable, controlling for all other variables.

L cutoff, which is comparable to the values observed in previous studies $[28,38]$. However, in our study, $78 \%$ of individuals of East Asian ancestry and $77 \%$ of individuals of South Asian ancestry had 25(OH)D concentrations lower than $40 \mathrm{nmol} / \mathrm{L}$. These findings demonstrate that while low concentrations of vitamin D were common during wintertime in young adults living in Canada, those of East Asian and South Asian ancestry had vitamin D concentrations that were much lower than their European counterparts.

In our sample, wintertime vitamin D status appears to be affected by both total vitamin $\mathrm{D}$ intake and skin pigmentation. The observation that wintertime $25(\mathrm{OH}) \mathrm{D}$ levels were primarily influenced by total vitamin D intake is not surprising, given that there is insufficient UVB for cutaneous vitamin D synthesis during the winter months in Canada [15]. Our finding that there was a significant inverse relationship between skin pigmentation and wintertime serum $25(\mathrm{OH}) \mathrm{D}$ concentrations seems to suggest that, when there is sufficient UVB for vitamin D synthesis (late spring, summer and early fall), melanin interferes with the production of vitamin $\mathrm{D}$ and this differential cutaneous production of vitamin $\mathrm{D}$ is reflected in wintertime 25(OH)D levels [46-48]. Our results are consistent with those of a recently published study [46] which showed that skin pigmentation (measured quantitatively using a reflectometer) had a significant effect on both basal $25(\mathrm{OH}) \mathrm{D}$ levels and the rates of increase of 25(OH)D after UVB exposure. Although other studies have noticed the effects of age $[18]$ and obesity $[22,49]$ on serum $25(\mathrm{OH}) \mathrm{D}$, these relationships were not observed in our study, likely because our participants were exclusively young adults (18-30 years) who showed more limited variation in BMI and WHR (Table 1) than earlier studies $[18,20,21,49]$.

Little is known about the vitamin D intake of non-First Nations Canadians who self-report non-European ances- try [50]. Our results indicate that the mean total vitamin D intake from food and supplements in individuals of East Asian and South Asian ancestry was lower than the current Health Canada recommendation for young adults of $200 \mathrm{IU} /$ day [29]. Our study suggests that those at greatest risk of vitamin D insufficiency are consuming the lowest amounts of vitamin $\mathrm{D}$ in their diet and/or supplemental sources. Even consuming the amount of vitamin D currently recommended by Health Canada does not prevent vitamin D insufficiency during the winter in samples consisting primarily of Canadians of European-ancestry [28].

Our study has a number of limitations. The sample was primarily comprised of young adults recruited at the University of Toronto, and may not reflect the general population of young people in Canada. Additionally, we did not explore the seasonal variation in vitamin $\mathrm{D}$ levels. The sample only featured three well represented population groups, and obviously does not encompass the great population diversity found in Canada, and more particularly, in Canadian metropolitan areas [39]. However, it should be noted that our sample better represented the population diversity of the Greater Toronto Area than previous studies. The 2006 Canadian census found that visible minorities represent $42.9 \%$ of the population of Toronto and $49 \%$ of the population of Mississauga [39]. Individuals of South Asian, Chinese and African Canadian ancestry make up the three largest visible minorities of the Toronto area and represent $31 \%$ of all the visible minorities in the city of Toronto. In the city of Mississauga, $41 \%$ of all visible minorities are of South Asian ancestry [39]. We are currently working on a study that will examine the seasonal variation in vitamin D status in a much larger sample that will better reflect the diverse demographic makeup of Canada.

\section{Conclusion}

Our study suggests that the prevalence of low vitamin D levels in young adults living in Canada (Southern Ontario) may be higher than previously described. Our sample included individuals of diverse ancestry, and as such provides a better representation of the multi-ethnic composition of Canadian metropolitan areas than previous studies. Our research also indicates that there are differences in serum 25(OH)D levels and vitamin D intake between population groups and that the currently Recommended Adequate Intake of vitamin D (RAI = $200 \mathrm{IU} /$ day) may not be met by a large proportion of the young adults. Vitamin D intake was particularly low amongst those young Canadians at greatest risk of vitamin D insufficiency. Furthermore, our study suggests that the current vitamin D recommendations in the US and Canada (200 $\mathrm{IU} /$ day) are insufficient to ensure optimal circulating 
25(OH)D levels, which are defined by most vitamin D experts as $75 \mathrm{nmol} / \mathrm{L}[27,36]$.

The Canadian Cancer Society has recently recommended that a vitamin D supplement of $1000 \mathrm{IU} /$ day be taken by all Canadian adults during the fall and winter, and that those at increased risk should consider year round supplementation [51]. Other Canadian organizations have also recommended higher intakes (800-2000 IU) for adults [51-53]. Although further research is needed to determine the vitamin $\mathrm{D}$ requirements of individuals of diverse ancestry living in Canada, the results of our study support the need for higher vitamin $D$ intakes to improve the overall health of young Canadians, and the need for food fortification strategies to meet these requirements.

\section{Competing interests}

RV and DEC have received funding from the Dairy Farmers of Canada. SW has received honoraria from the Dairy Farmers and the Dairy Council. RV has served as a consultant to, or has received honoraria from Cytochroma, Ddrops Company, Merck, Novartis, and Wyeth.

\section{Authors' contributions}

AG participated in the design and coordination of the study, carried out recruitment, collected the anthropological and pigmentation measurements, helped to design the personal and UVR questionnaires, performed the statistical analyses, and drafted the manuscript. JLB helped in the recruitment and implementation of the study, and helped to draft the manuscript. HW carried out the nutritional analyses of the 7-day food diary. DW performed the serum 25(OH)D biochemical analyses and helped to draft the manuscript. DEC helped in the designed of the study and helped draft the manuscript. RV supervised the biochemical analyses, helped with the design of the UVR questionnaire and helped to draft the manuscript. SW designed the 7-day food diary, supervised the nutritional analyses, and helped to draft the manuscript. EP conceived of the study, and participated in its design and coordination, helped to design the personal and UVR questionnaires helped with statistical analysis and helped to draft the manuscript. All authors read and approved the final manuscript.

\section{Acknowledgements}

We would like to thank the study subjects for their participation. We are also thankful to Emily Cameron and the nursing staff of the University of Toronto at Mississauga Health Services for their key contribution to this project. DEC and RV have received research support from NSERC and the Dairy Farmers of Canada. EJP is supported by an Early Researcher Award from the Ministry of Research and Innovation, Government of Ontario and by NSERC.

\section{References}

I. Stumpf WE, Sar M, Reid FA, Tanaka Y, DeLuca HF: Target cells for I,25-dihydroxyvitamin D3 in intestinal tract, stomach, kid- ney, skin, pituitary, and parathyroid. Science 1979, 206(4423): I I88-1190.

2. Reichel H, Norman AW: Systemic effects of vitamin D. Annu Rev Med 1989, 40:7I-78.

3. MacDonald PN: Molecular biology of the vitamin D receptor. In Vitamin D: Molecular Biology, Physiology, and Clinical Applications Edited by: Holick MF. Totowa, NJ: Humana Press; 1999: 109-128.

4. Holick MF: Vitamin D: A millennium perspective. J Cell Biochem 2003, 88(2):296-307.

5. Lappe JM, Travers-Gustafson D, Davies KM, Recker RR, Heaney RP: Vitamin $D$ and calcium supplementation reduces cancer risk: results of a randomized trial. Am J Clin Nutr 2007, 85(6): I586-|59|.

6. Holick MF: The vitamin D epidemic and its health consequences. J Nutr 2005, I35( I I):2739S-2748S.

7. Giovannucci $E$ : The epidemiology of vitamin $D$ and cancer incidence and mortality: a review (United States). Cancer Causes Control 2005, 16(2):83-95.

8. Garland CF, Garland FC, Gorham ED, Lipkin M, Newmark H, Mohr SB, Holick MF: The role of vitamin $\mathbf{D}$ in cancer prevention. Am J Public Health 2006, 96(2):252-26I.

9. Zasloff M: Fighting infections with vitamin D. Nat Med 2006, I 2(4):388-390.

10. Liu PT, Stenger S, Li H, Wenzel L, Tan BH, Krutzik SR, Ochoa MT, Schauber J, Wu K, Meinken C, et al:: Toll-like receptor triggering of a vitamin D-mediated human antimicrobial response. Science 2006, 3 II(5768): I770-I773.

II. Holick MF: Vitamin D: Important for prevention of osteoporosis, cardiovascular heart disease, type I diabetes, autoimmune diseases, and some cancers. South Med J 2005, 98(10): 1024-1027.

12. Holick MF: Vitamin D deficiency. N Engl J Med 2007, 357(3):266-28I.

13. Giovannucci E, Liu Y, Hollis BW, Rimm EB: 25-hydroxyvitamin D and risk of myocardial infarction in men: a prospective study. Arch Intern Med 2008, 168(I I): I I74-I I 80.

14. Holick MF: Vitamin D: importance in the prevention of cancers, type I diabetes, heart disease, and osteoporosis. Am J Clin Nutr 2004, 79(3):362-37I.

15. Webb AR, Kline L, Holick MF: Influence of Season and Latitude on the Cutaneous Synthesis of Vitamin-D3 - Exposure to Winter Sunlight in Boston and Edmonton Will Not Promote Vitamin-D3 Synthesis in Human-Skin. J Clin Endocrinol Metab 1988, 67(2):373-378.

16. Clemens TL, Adams JS, Henderson SL, Holick MF: Increased skin pigment reduces the capacity of skin to synthesise vitamin D3. Lancet I982, I(8263):74-76.

17. Matsuoka LY, Wortsman J, Chen TC, Holick MF: Compensation for the interracial variance in the cutaneous synthesis of vitamin D. I Lab Clin Med 1 995, I 26(5):452-457.

18. MacLaughlin J, Holick MF: Aging decreases the capacity of human skin to produce vitamin D3. J Clin Invest 1985, 76(4): 1536-1538.

19. Compston JE, Vedi S, Ledger JE, Webb A, Gazet JC, Pilkington TR: Vitamin $D$ status and bone histomorphometry in gross obesity. Am J Clin Nutr 198I, 34(I I):2359-2363.

20. Arunabh S, Pollack S, Yeh J, Aloia JF: Body fat content and 25hydroxyvitamin D levels in healthy women. J Clin Endocrinol Metab 2003, 88(1):157-161.

21. Parikh SJ, Edelman M, Uwaifo GI, Freedman RJ, Semega-Janneh M, Reynolds J, Yanovski JA: The Relationship between Obesity and Serum I,25-Dihydroxy Vitamin D Concentrations in Healthy Adults. J Clin Endocrinol Metab 2004, 89(3): I I96-I I 99.

22. Wortsman J, Matsuoka LY, Chen TC, Lu Z, Holick MF: Decreased bioavailability of vitamin D in obesity. Am J Clin Nutr 2000, 72(3):690-693.

23. Holick MF: Sunlight and vitamin D for bone health and prevention of autoimmune diseases, cancers, and cardiovascular disease. Am J Clin Nutr 2004, 80(6): 1678S-1688S.

24. Lo CW, Paris PW, Clemens TL, Nolan J, Holick MF: Vitamin D absorption in healthy subjects and in patients with intestinal malabsorption syndromes. Am J Clin Nutr 1985, 42(4):644-649.

25. Zhou C, Assem M, Tay JC, Watkins PB, Blumberg B, Schuetz EG, Thummel KE: Steroid and xenobiotic receptor and vitamin $D$ receptor crosstalk mediates CYP24 expression and druginduced osteomalacia. J Clin Invest 2006, I 16(6): 1703-1712. 
26. Holick MF: Vitamin D Status: Measurement, Interpretation, and Clinical Application. Ann Epidemiol 2008 in press

27. Bischoff-Ferrari HA, Giovannucci E, Willett WC, Dietrich T, DawsonHughes B: Estimation of optimal serum concentrations of 25 hydroxyvitamin D for multiple health outcomes. Am J Clin Nutr 2006, 84(I): 18-28

28. Vieth R, Cole DE, Hawker GA, Trang HM, Rubin LA: Wintertime vitamin $D$ insufficiency is common in young Canadian women, and their vitamin $\mathrm{D}$ intake does not prevent it. Eur Clin Nutr 200 I, 55(I 2): 109I-I097.

29. Standing Committee on the Scientific Evaluation of Dietary Reference Intakes: Dietary Reference Intakes for Calcium, Phosphorus, Magnesium, Vitamin D, and Fluoride Washington, DC: National Academy Press; 1997.

30. Zittermann A: Vitamin D and disease prevention with special reference to cardiovascular disease. Prog Biophys Mol Biol 2006, 92(I):39-48

31. Need AG, Horowitz M, Morris HA, Nordin BC: Vitamin D status: effects on parathyroid hormone and I, 25-dihydroxyvitamin D in postmenopausal women. Am 」 Clin Nutr 2000 7I(6):1577-|58|.

32. Malabanan A, Veronikis IE, Holick MF: Redefining vitamin D insufficiency. Lancet 1998, 35 I (9 I 05):805-806.

33. Chapuy MC, Preziosi P, Maamer M, Arnaud S, Galan P, Hercberg S, Meunier PJ: Prevalence of vitamin $D$ insufficiency in an adult normal population. Osteoporos Int 1997, 7(5):439-443.

34. Thomas MK, Lloyd-Jones DM, Thadhani RI, Shaw AC, Deraska DJ, Kitch BT, Vamvakas EC, Dick IM, Prince RL, Finkelstein JS: Hypovitaminosis $\mathbf{D}$ in medical inpatients. N Engl J Med 1998, 338(1 2): 777-783.

35. Heaney RP, Dowell MS, Hale CA, Bendich A: Calcium absorption varies within the reference range for serum 25-hydroxyvitamin D. J Am Coll Nutr 2003, 22(2): $142-146$.

36. Vieth $R$, Bischoff-Ferrari $H$, Boucher BJ, Dawson-Hughes B, Garland CF, Heaney RP, Holick MF, Hollis BW, Lamberg-Allardt C, McGrath J], et al.: The urgent need to recommend an intake of vitamin D that is effective. Am / Clin Nutr 2007, 85(3):649-650.

37. Holick MF, Chen TC: Vitamin D deficiency: a worldwide problem with health consequences. Am J Clin Nutr 2008, 87(4): I080S- I086S

38. Rucker D, Allan JA, Fick GH, Hanley DA: Vitamin D insufficiency in a population of healthy western Canadians. CMAJ 2002 166(12): 1517-1524.

39. Chui T, Tran K, Maheux H: Canada's Ethnocultural Mosaic, 2006 Census. Edited by: Canada S. Ottawa: Minister of Industry; 2008.

40. Chen TC, Chimeh F, Lu ZR, Mathieu J, Person KS, Zhang AQ, Kohn $\mathrm{N}$, Martinello S, Berkowitz R, Holick MF: Factors that influence the cutaneous synthesis and dietary sources of vitamin $D$. Arch Biochem Biophys 2007, 460(2):213-217.

4I. Jablonski NG, Chaplin G: The evolution of human skin coloration. J Hum Evol 2000, 39(I):57-106.

42. Shriver MD, Parra EJ: Comparison of narrow-band reflectance spectroscopy and tristimulus colorimetry for measurements of skin and hair color in persons of different biological ancestry. Am J Phys Anthropol 2000, I I 2(I): 17-27.

43. Diffey BL, Oliver RJ, Farr PM: A portable instrument for quantifying erythema induced by ultraviolet radiation. $\mathrm{Br}$ J Dermatol 1984, I II (6):663-672.

44. Faul F, Erdfelder E, Lang AG, Buchner A: G*Power 3: A flexible statistical power analysis program for the social, behavioural and biomedical sciences. Behav Res Methods 2007, 39(2): 175-191.

45. Burgaz A, Akesson A, Oster A, Michaelsson K, Wolk A: Associations of diet, supplement use, and ultraviolet $B$ radiation exposure with vitamin D status in Swedish women during winter. Am / Clin Nutr 2007, 86(5): 1399-1404.

46. Armas LAG, Dowell S, Akhter M, Duthuluru S, Huerter C, Hollis BW, Lund R, Heaney RP: Ultraviolet-B radiation increases serum 25-hydroxyvitamin $D$ levels: The effect of UVB dose and skin color. J Am Acad Dermatol 2007, 57(4):588-593

47. Mawer EB, Backhouse J, Holman CA, Lumb GA, Stanbury SW: The distribution and storage of vitamin $D$ and its metabolites in human tissues. Clin Sci 1972, 43(3):41 3-43|.

48. Rosenstreich SJ, Rich C, Volwiler W: Deposition in and release of vitamin D3 from body fat: evidence for a storage site in the rat. J Clin Invest |97|, 50(3):679-687.
49. Liel Y, Ulmer E, Shary J, Hollis BW, Bell NH: Low circulating vitamin D in obesity. Calcif Tissue Int 1988, 43(4): 199-20I.

50. Calvo MS, Whiting SJ, Barton CN: Vitamin D fortification in the United States and Canada: current status and data needs. Am J Clin Nutr 2004, 80(6 Suppl): 1710S-1716S.

51. Canadian Cancer Society Announces Vitamin D Recommendation [http://www.cancer.ca/ccs/internet/mediareleaselist/ $0,3208,3172 \quad 1613121606 \quad 1997621989$ langid-en, 00.html]

52. Vitamin D: A key factor in good calcium absorption [http:// www.osteoporosis.ca/english/About\%200steoporosis/Nutrition/ Vitamin\%20D/default.asp?s=I]

53. Safe and effective way to maintain adequate levels of vitamin D vitamin d.html] [http://www.dermatology.ca/media/position statement/

\section{Pre-publication history}

The pre-publication history for this paper can be accessed here:

http://www.biomedcentral.com/1471-2458/8/336/pre pub

Publish with Biomed Central and every scientist can read your work free of charge

"BioMed Central will be the most significant development for disseminating the results of biomedical research in our lifetime. "

Sir Paul Nurse, Cancer Research UK

Your research papers will be:

- available free of charge to the entire biomedical community

- peer reviewed and published immediately upon acceptance

- cited in PubMed and archived on PubMed Central

- yours - you keep the copyright 